\title{
Accelerating water dissociation in bipolar membranes and for electrocatalysis
}

\author{
Sebastian Z. Oener*, Marc J. Foster, Shannon W. Boettcher* \\ Department of Chemistry and Biochemistry, the Materials Science Institute, and the Oregon Center for Electrochemistry, University of Oregon, Eugene, OR 97403, USA. \\ *Corresponding author. Email: szo@uoregon.edu (S.Z.O.); swb@uoregon.edu (S.W.B.)
}

Catalyzing water dissociation (WD) into protons and hydroxide ions is important both for fabricating bipolar membranes (BPMs) that can couple different pH environments into a single electrochemical device, and for accelerating electrocatalytic reactions that consume protons in neutral-to-alkaline media. We designed a BPM electrolyzer to quantitatively measure WD kinetics and show that, for metal nanoparticles, WD activity correlates with alkaline hydrogen-evolution-reaction activity. By combining metal-oxide WD catalysts efficient near the acidic proton-exchange layer with those efficient near the alkaline hydroxideexchange layer, we demonstrate a BPM driving WD with overpotentials of $<10 \mathrm{mV}$ at $20 \mathrm{~mA} \cdot \mathrm{cm}^{-2}$ and purewater BPM electrolyzers that operate with an alkaline anode and acidic cathode at $500 \mathrm{~mA} \cdot \mathrm{cm}^{-2}$ with a total electrolysis voltage of $\sim 2.2 \mathrm{~V}$.

Bipolar membranes (BPMs) consist of a polymeric cation-exchange layer (CEL) with fixed anionic groups and mobile cations, in contact with an anion-exchange layer (AEL) with fixed cationic groups and mobile anions (1). When a sufficient bias is applied across a BPM, heterolytic water dissociation (WD), $\mathrm{H}_{2} \mathrm{O} \rightarrow \mathrm{H}^{+}+\mathrm{OH}^{-}$, occurs at the AEL/CEL interface with the $\mathrm{H}^{+}$driven through the $\mathrm{CEL}$ and the $\mathrm{OH}^{-}$driven through the AEL (Fig. 1) (2). BPMs are used in electrodialysis, desalination, acid/base synthesis, or other electrochemical applications where a steady-state difference in $\mathrm{pH}$ across the membrane is needed (3). Emerging applications include the use of BPMs in water (photo)electrolysis $\left(2 \mathrm{H}_{2} \mathrm{O} \rightarrow 2 \mathrm{H}_{2}+\mathrm{O}_{2}\right)$ where the anode and cathode electrocatalyst can operate at different local $\mathrm{pH}$ at steady state (4), $\mathrm{CO}_{2}$ electrolyzers where BPMs attenuate dissolved (bi)carbonate crossover due to the outward flux of $\mathrm{H}^{+} / \mathrm{OH}^{-}(5-9)$, or regenerative fuel cells that provide ideal $\mathrm{pH}$ conditions for bidirectional electrocatalysts (10).

State-of-the-art research and commercial BPMs typically show substantial overpotentials driving water dissociation $\left(\eta_{\text {wd }}\right)$ of $\gtrsim 100 \mathrm{mV}$ even at current densities of only $\sim 20$ $\mathrm{mA} \cdot \mathrm{cm}^{-2}$ (table S1; see supplementary text and figs. S1 and S2 for precise definition of $\eta_{\mathrm{wd}}$ including theory and simulation of BPMs). The best-reported BPM uses a three-dimensional (3D) electrospun AEL/CEL junction that passes $\sim 0.5 \mathrm{~A} \cdot \mathrm{cm}^{-2}$ at $\eta_{\mathrm{wd}} \sim 0.6 \mathrm{~V}$, with $\mathrm{Al}(\mathrm{OH})_{3}$ nanoparticles catalyzing $\mathrm{WD}$ at the AEL/CEL interface and neutral salt solutions on both sides of the membranes (11). These $\eta_{\mathrm{wd}}$ values are too high for energy-conversion applications that require $\eta_{\mathrm{wd}}<100 \mathrm{mV}$ at 1 to $2 \mathrm{~A} \cdot \mathrm{cm}^{-2}$.

To improve BPM performance the WD reaction must be accelerated. The addition of polymers, such as sulfonated polyether ether ketone (12), or metal (hydr)oxide WD catalysts in the $\mathrm{BPM}$ junction, e.g., $\mathrm{Al}_{2} \mathrm{O}_{3}, \mathrm{Fe}(\mathrm{OH})_{3}$ and $\mathrm{Cr}(\mathrm{OH})_{3}$, can reduce $\eta_{\mathrm{wd}}$ compared to BPMs without catalyst (13-17). WD catalysts have also been introduced by precipitation of metal salts (17), via sol-gel chemistry (14), or by the addition of nanoparticles (15). Previous studies investigated few WD catalysts at a time or focused on the membrane end groups at the AEL/CEL interface (18-22), and usually treated WD as occurring in a homogeneous $\mathrm{pH}$-neutral layer. Other polymers are often added in the junction to physically link the constituent layers and a variety of ionomer membranes (with different chemical end groups and thus different inherent WD kinetics) have been used across different studies. Sometimes membranes are physically roughened prior to assembly (23). So far, no systematic and comprehensive studies of WD as a function of catalyst composition and location inside the BPM junction have been reported, no consistent mechanistic picture has emerged, and the resulting BPM performance is insufficient for emerging applications $(24,25)$.

Beyond BPMs, WD is important for any chemical reaction that uses water as a reactant. Understanding fundamental WD mechanisms in pure water, and the reverse $\mathrm{H}^{+} / \mathrm{OH}^{-}$recombination reaction, has been a focus of experiment and theory for decades (26-28). The related dissociative adsorption of water, $\mathrm{H}_{2} \mathrm{O} \rightarrow \mathrm{H}_{\mathrm{ad}}+\mathrm{OH}_{\mathrm{ad}}$, occurs on surfaces and is important when water reacts in thermochemical processes, such as for water-gas-shift catalysis (29). The interaction of water with surfaces has thus been of longstanding interest (30), with broad importance to corrosion, passivation, and geological processes (31). In biology, metalloenzymes activate water. Carbonic anhydrase, for example, binds water to $\mathrm{Zn}^{2+}$ and releases $\mathrm{H}^{+}$to generate nucleophilic $\mathrm{OH}^{-}$that reacts with 
$\mathrm{CO}_{2}$ to form $\mathrm{HCO}_{3}^{-}$(32). During the alkaline hydrogen-evolution reaction (HER, $2 \mathrm{H}_{2} \mathrm{O}+2 \mathrm{e}^{-} \rightarrow \mathrm{H}_{2}+2 \mathrm{OH}^{-}$), important for low-cost alkaline water electrolysis (33), the first step involves WD coupled with the formation of a surface metal hydride $\left(\mathrm{H}_{2} \mathrm{O}+\mathrm{M}^{*}+\mathrm{e}^{-} \rightarrow \mathrm{M}-\mathrm{H}+\mathrm{OH}^{-}\right)$and is thought to be rate limiting. Modification of metals with hydroxides, proposed to catalyze WD, substantially increases HER activity via a proposed bifunctional mechanism $(34,35)$, but alternative explanations have been proposed (36-38). No direct measurements of the isolated WD step, independent from the other reaction steps, have been conducted on electrocatalysts. WD was also hypothesized to affect the rate of electrocatalytic $\mathrm{CO}_{2}$ reduction-a reaction that occurs in neutral-to-basic $\mathrm{pH}$ and therefore must use water as a proton source (39).

Here we report the use of a BPM electrolyzer (Fig. 1) to measure WD kinetics on $\sim 40$ metal and metal-oxide nanoparticle assemblies, composed of $\sim 30$ different materials. The electrolyzer was fed only $18.2 \mathrm{M} \Omega \cdot \mathrm{cm}$ water (without supporting electrolyte that might complicate results; Fig. 1A). The BPMs were encompassed in a membrane-electrode assembly (MEA) held under pressure by two rigid current collectors (Ti/Pt-frit) to prevent delamination and ensure constant contact between the gas-diffusion electrodes, membranes and WD-catalyst layers. As different WD catalysts were studied, the materials and preparation parameters used for the MEA were kept constant.

The voltage needed for BPM electrolysis $\left(V_{\text {tot }}\right)$ can be conceptually decomposed into: (i) the thermodynamic potential of generating $\mathrm{O}_{2}$ in alkaline media and $\mathrm{H}_{2}$ in acidic media $\left(E_{\mathrm{H}^{+} / \mathrm{H}_{2}}^{0 \text {,aci }}-E_{\mathrm{O}_{2} / \mathrm{OH}^{-}}^{0, \text { base }}=-0.40 \mathrm{~V}\right.$, although, rigorously, the reference half-reactions that define the $E^{0}$ on each side of the BPM are at different electrostatic potentials), (ii) the OER and HER overpotentials at a given current density $\left(\eta_{\mathrm{OER}}\right.$ and $\eta_{\mathrm{HER}}$, respectively), (iii) the thermodynamic potential needed to generate acid and base from a neutral aqueous solution ( $E_{\mathrm{wd}}^{0}=-\Delta G_{\mathrm{wd}}^{0} / F=-0.83 \mathrm{~V}$ at standard conditions), (iv) $\eta_{\mathrm{wd}}$ (defined to be positive here), and (v) the voltage loss due to ohmic resistance, which is negligible at $20 \mathrm{~mA} \cdot \mathrm{cm}^{-2}$ for the MEA setup (40). We find $V_{\text {tot }}$ depends sensitively on the WD catalyst.

To quantify $\eta_{\mathrm{wd}}$ independent of the anode and cathode reactions, we built an H-cell that maintains the BPM MEA under pressure while contacting the CEL with $1.0 \mathrm{M}$ acid and the AEL with $1.0 \mathrm{M}$ base (Fig. 1B). The electrostatic potential across the BPM was measured using two $\mathrm{pH}$-independent $\mathrm{Ag} / \mathrm{AgCl}$ reference electrodes in the basic and acidic compartments while a constant current was passed between the anode and cathode (2). The $\eta_{\text {wd }}$ values are taken as the increase in the magnitude of the electrostatic potential over the expected equilibrium value as a function of the current density (see the supplementary materials). Because we used high- conductivity electrolytes, and the anode/cathode were in direct contact with the BPM, resistive voltage losses between the BPM and reference electrodes were negligible (fig. S3). By measuring a BPM made with the same $\mathrm{IrO}_{2} \mathrm{WD}$ catalyst in both the $\mathrm{H}$-cell and pure-water electrolyzer, we calculated a theoretical electrolyzer baseline for $\eta_{\mathrm{wd}}=0 \mathrm{~V}$ (figs. S4 to S7). Voltages measured for the BPM electrolyzer above this baseline are taken as $\eta_{\mathrm{wd}}$.

The use of an electrolyzer to study WD kinetics inside the BPM instead of a conventional H-cell is important. We feed pure water, thereby eliminating co-ion (e.g., $\mathrm{K}^{+}, \mathrm{Cl}^{-}$) crossover in the conventional H-cell measurements that could carry current and potentially influence the WD reaction at the $\mathrm{AEL} / \mathrm{CEL}$ junction through ion adsorption $(36,41,42)$. In the pure-water BPM electrolyzer, current is only carried by $\mathrm{H}^{+}$ and $\mathrm{OH}^{-}$. We use $\mathrm{IrO}_{2} \mathrm{WD}$ catalysts to calibrate the electrolyzer with the $\mathrm{H}$-cell measurements because $\mathrm{IrO}_{2}$ is stable under acidic and alkaline conditions. Co-ions in the H-cell setup are responsible for less than $2 \%$ of the current at $20 \mathrm{~mA} \cdot \mathrm{cm}^{-2}$ (fig. S35).

The calibrated BPM electrolyzer was used to study WD kinetics on metal-oxide nanoparticles deposited in the BPM junction (table S2). We find that $\eta_{\mathrm{wd}}$ is relatively insensitive to loading, once the membrane is covered with 100 to 200 $\mathrm{nm}$ of WD catalyst (see figs. S8 and S9). Because metal-oxide surfaces are polyacids/polybases, their surface chemistry and protonation state depend on $\mathrm{pH}$, which could affect WD kinetics $(43,44)$. The CEL surface is an acidic environment whereas the AEL surface is alkaline. To study the WD catalysis under a defined local $\mathrm{pH}$, we used a chemically stable WD catalyst at one surface (e.g., $\mathrm{NiO}$ at the AEL, and $\mathrm{Sb}: \mathrm{SnO}_{2}$ at the CEL) while systematically varying the WD catalyst at the other membrane surface (polarization curves are shown in figs. S10 to S15). We separately measured each oxide's point of zero charge (PZC; fig. S16 and table S2) to assess acid-base properties and plot WD catalyst activity versus PZC in Fig. 2. With $\mathrm{Sb}: \mathrm{SnO}_{2}$ on the acidic CEL, the best WD catalysts on the basic AEL tend to be those with basic PZCs, such as NiO. With $\mathrm{NiO}$ on the basic AEL, the best WD catalysts on the acidic CEL are those with acidic PZCs, such as $\mathrm{IrO}_{2}$ or $\mathrm{SnO}_{2}$. At higher current densities, and hence larger $\eta_{w d}$, these weak correlations appear more pronounced (fig. S17).

A proton-transfer mechanism, similar to the one proposed for WD catalysis by ionomer-membrane end groups at the AEL/CEL interface $(18,19,22)$, can be used to tentatively rationalize the data in Fig. 2. Under basic conditions at the AEL, most oxide surfaces are negatively charged and consist of structurally diverse $-\mathrm{OH}$ and $-\mathrm{O}^{-}$species. These sites might act as proton donors or acceptors, respectively, catalyzing WD via a two-step mechanism: 


$$
\begin{gathered}
\mathrm{MO}^{-}+\mathrm{H}_{2} \mathrm{O} \stackrel{k_{1}}{\rightleftarrows} \mathrm{MOH}+\mathrm{OH}^{-}(1) \\
k_{1}^{\prime} \\
k_{2} \\
\mathrm{MOH}+\mathrm{H}_{2} \mathrm{O} \stackrel{\mathrm{MO}^{-}+\mathrm{H}_{3} \mathrm{O}^{+}(2)}{\rightleftarrows}
\end{gathered}
$$

In the above case, $\mathrm{MO}^{-}$would be a catalyst active site, with $\mathrm{MOH}$ an intermediate. Under acidic conditions at the CEL, most oxide surfaces will be protonated, consisting of $-\mathrm{OH}_{2}{ }^{+}$ and -OH species, and can similarly catalyze WD:

$$
\begin{gathered}
\mathrm{MOH}_{2}^{+}+\mathrm{H}_{2} \mathrm{O} \stackrel{k_{3}}{\rightleftarrows} \mathrm{MOH}+\mathrm{H}_{3} \mathrm{O}^{+}(3) \\
k_{3}{ }^{\prime} \\
k_{4}{ }^{\mathrm{MOH}+\mathrm{H}_{2} \mathrm{O}} \stackrel{\mathrm{MOH}_{2}^{+}+\mathrm{OH}^{-}(4)}{\rightleftarrows} k_{4}{ }^{\prime}
\end{gathered}
$$

A large net rate for either of the above two-step mechanisms require significant concentrations of both the protonated and unprotonated surface species (assuming similarity of the forward rate constants $k_{1}$ and $k_{2}$ or $k_{3}$ and $k_{4}$ ), so that both steps are simultaneously fast. At local-pH values near the PZC, a diversity of surface-protonation states capable of driving both steps is needed for fast WD. Although this is consistent with the observation that oxide WD catalysts tend to work best when the local $\mathrm{pH}$ is near the PZC, the weak trends in Fig. 2 illustrate that other factors, such as accessible surface area, the diversity and range of surface $\mathrm{p} K_{\mathrm{a}}$, and density of surface hydroxyl groups, are also likely to affect WD activity. For materials without a significant density of ionizable surface groups (e.g., noble metals) PZC data are unlikely to be useful.

Although alternative mechanisms involving the dissociative adsorption of water to form $\mathrm{M}-\mathrm{OH}$ intermediates are also possible (see the supplementary materials), we hypothesize these pathways are slow on typical oxides due to the strength of the M-O bonds. Such mechanisms may be prevalent on the precious metals discussed below. A few oxides, e.g., $\mathrm{TiO}_{2}$ and $\mathrm{SiO}_{2}$, catalyze WD reasonably in both acidic and basic environments. This may be due to a broad surface-p $K_{\mathrm{a}}$ range for $\mathrm{TiO}_{2}$ and $\mathrm{SiO}_{2}(45,46)$ better described as "spectra" than discrete $\mathrm{p} K_{\mathrm{a}}(44)$. Some oxides are also not stable in acid or base. $\mathrm{NiO}$, for example, would partially dissolve on the CEL surface generating soluble $\mathrm{Ni}^{2+}$ that can ion-exchange for $\mathrm{H}^{+}$in the CEL. Improved mechanistic insight will require better understanding the WD-catalyst surface speciation. Raman and Stark-effect spectroscopy, for example, might be suitable to detect chemical changes on the catalyst surface during operation and help elucidate the role of the electric field in the junction, respectively.
These findings suggest a new principle for the design of WD catalysts that accounts for the surface speciation and chemical stability of the catalyst at the relevant local $\mathrm{pH}$. In the context of BPMs, the data show the superiority of using two WD catalyst layers selected for the appropriate local $\mathrm{pH}$ over a single material as in prior work. We envision designing multilayered WD catalysts that provide a gradient in surface acid/base behavior matched to the $\mathrm{pH}$ gradient present at the $\mathrm{AEL} / \mathrm{CEL}$ interface at the operational current density.

The new data also suggest that catalysis of WD is more important than electric-field enhancement (Onsager's theory of the second Wien effect) in the BPM junction, a topic of a long-standing debate $(18,24,47,48)$. The electric field across the AEL/CEL junction is $\sim 3 \cdot 10^{4} \mathrm{~V} \cdot \mathrm{cm}^{-1}$, assuming the electrostatic potential drops linearly across a $\sim 300$-nm-thick WDcatalyst layer. This field is not sufficient to substantially increase the rate of WD based on Onsager's theory (see the supplementary materials) (47), consistent with previous calculations (49). We observe no apparent correlation between $\eta_{\mathrm{wd}}$ and the electronic properties of the oxide. Electrical conductors $\left(\mathrm{IrO}_{2}, \mathrm{RuO}_{2}\right), n$ - and $p$-type semiconductors $\left(\mathrm{SnO}_{2}, \mathrm{NiO}\right)$, and insulators $\left(\mathrm{SiO}_{2}\right)$ all modify/screen the electric-field distribution inside the WD-catalyst layer differently, yet are all efficient WD catalysts. The $\eta_{\mathrm{wd}}$ values are also temperature dependent (fig. S18). The BPM made without added WD catalyst has the narrowest junction, sharpest electrochemical potential gradient, and thus the largest electric field, but the performance is the worst (see below). These findings suggest the rates of WD are influenced primarily by surface catalysis in the presence of $\bar{\mu}_{\mathrm{H}^{+}}$and $\bar{\mu}_{\mathrm{OH}^{-}}$gradients that separate $\mathrm{H}^{+}$from $\mathrm{OH}^{-}$, with electric-field enhancement playing a secondary role.

WD has further been proposed to be rate-determining in some electrocatalytic reactions. During the HER in alkaline media $\left(2 \mathrm{H}_{2} \mathrm{O}+2 \mathrm{e}^{-} \rightarrow \mathrm{H}_{2}+2 \mathrm{OH}^{-}\right)$, the first step $\left(\mathrm{H}_{2} \mathrm{O}+\mathrm{e}^{-} \rightarrow \mathrm{H}_{\mathrm{ad}}\right.$ $+\mathrm{OH}^{-}$) involves $\mathrm{WD}$ and metal-hydride formation and is thought to be the reason HER is slower in base than in acid $(34,35)$. The OER under acidic or neutral conditions, $2 \mathrm{H}_{2} \mathrm{O} \rightarrow$ $\mathrm{O}_{2}+4 \mathrm{H}^{+}+4 \mathrm{e}^{-}$, likewise requires WD to generate $-\mathrm{OH}_{\mathrm{ad}}$ species that can be further oxidized. WD, however, is not thought rate-limiting for the OER (50). A fundamental challenge is the inability to isolate and measure the WD kinetics for a particular electrocatalyst independent of other electrochemical processes. Traditionally, the driving force for both WD and electron transfer is simultaneously provided as an applied electrode potential. Here we isolate WD kinetics by locally generating a gradient in the electrochemical potentials $\bar{\mu}_{\mathrm{H}^{+}}$ and $\bar{\mu}_{\mathrm{OH}^{-}}$inside the electrically disconnected BPM junction (see the supplementary materials for simulations).

We used the BPM electrolyzer to measure $\eta_{\mathrm{wd}}$ of common HER and OER electrocatalysts (Fig. 3) and analyzed them to 
ascertain whether $\eta_{\mathrm{wd}}$ correlate with electrocatalytic overpotentials (at similar current density) measured for the same particles in a three-electrode cell (figs. S19 to S23). We find that $\eta_{\text {HER }}$ of precious-metal nanoparticles in $1.0 \mathrm{M} \mathrm{KOH}$ linearly correlates with $\eta_{\mathrm{wd}}$ measured at the basic AEL surface [Pearson correlation coefficient $\rho\left(\eta_{\mathrm{HER}}^{\text {base }}, \eta_{\mathrm{wd}}^{\mathrm{AEL}}\right)=-0.81$ ]. As $\eta_{\mathrm{wd}}$ tends to zero, so does $\eta_{\text {HER }}$ at a similar current density. When $\eta_{\text {HER }}$ for those metal nanoparticles are measured in $1.0 \mathrm{M}$ $\mathrm{H}_{2} \mathrm{SO}_{4}$, where WD is not needed for the HER, there is no significant correlation and $\rho\left(\eta_{\mathrm{HER}}^{\mathrm{acid}}, \eta_{\mathrm{wd}}^{\mathrm{AEL}}\right)=-0.131$.

The above correlation is consistent with the hypothesis that modifying metals like Pt with metal hydroxides such as $\mathrm{Ni}(\mathrm{OH})_{2}$ improves alkaline HER activity due to increased WD kinetics $(34,35)$. Our results show that $\mathrm{NiO}$ (which is hydroxylated in water) is an excellent alkaline WD catalyst, and further enable the design of new electrocatalysts. $\mathrm{TiO}_{2}$ is an active WD catalyst in both acid and base and is chemically stable. We deposited $\mathrm{TiO}_{2}$ by atomic-layer deposition (ALD) onto $\mathrm{Pt}$, Ir, $\mathrm{Ru}, \mathrm{Rh}, \mathrm{PtRu}$ and PtIr nanoparticles at $250^{\circ} \mathrm{C}$. The addition of $\mathrm{TiO}_{2}$ simultaneously decreased both $\eta_{\mathrm{wd}}$ and $\eta_{\mathrm{HER}}^{\text {base }}$ providing direct support to a bifunctional alkaline HER mechanism wherein the oxide facilitates WD and the metal stabilizes $\mathrm{M}-\mathrm{H}$ intermediates.

A water-ordering model has been alternatively proposed to explain the increased alkaline HER kinetics of metal-hydroxide-functionalized $\mathrm{Pt}$ (37). When water is dissociated during HER in base, $\mathrm{OH}^{-}$is produced and stabilized by orienting nearby water dipoles. Pt, under alkaline HER conditions, carries a significant surface charge, which also orients nearby water molecules and generates an energy barrier to water reorganization. $\mathrm{Ni}(\mathrm{OH})_{2}$ lowers the surface charge of $\mathrm{Pt}$ under alkaline HER conditions which could reduce the water-reorganization energy and thus perhaps $\eta_{\mathrm{HER}}^{\text {base }}(37)$. Although the general trends of PZC with WD rate (Fig. 2) are consistent with this hypothesis, some of our data are not. $\mathrm{SiO}_{2}$ has an acidic PZC, yet works well for WD in base where it presents charged surfaces that would, in the above model, be expected to retard $\mathrm{WD}$. $\mathrm{TiO}_{2}$ and $\mathrm{Ni}(\mathrm{OH})_{2}$ have very different PZCs, and thus are expected to have very different net surface-charge densities in base. Yet, both enhance alkaline HER kinetics on Pt and other metal surfaces. This evidence, along with the proposed proton-transfer WD mechanism (Eqs. 1-4), favors a bifunctional route for alkaline HER on (hydr)oxidefunctionalized metal surfaces. Further work is needed, however, to understand the effects of water ordering on WD activity for the oxides studied here that are likely to have a diversity of hydroxylated surface sites with a range of $\mathrm{p} K_{\mathrm{a}}$.

In contrast to alkaline HER, we didn't find a strong correlation between $\eta_{\mathrm{wd}}$ and the OER activity in acid $\left[\rho\left(\eta_{\mathrm{OER}}^{\text {acid }}, \eta_{\mathrm{wd}}^{\mathrm{CEL}}\right)\right.$ $=0.49]$ where $\mathrm{H}_{2} \mathrm{O}$ is also a reagent (Fig. $3 \mathrm{C}$ ), nor between $\eta_{\mathrm{wd}}$ and the OER activity in base $\left[\rho\left(\eta_{\mathrm{OER}}^{\mathrm{base}}, \eta_{\mathrm{wd}}^{\mathrm{CEL}}\right)=-0.45\right]$. This is consistent with computational models of OER indicating that non-optimal $\mathrm{M}-\mathrm{O}$ binding strengths provide rate-limiting barriers (50). It is, however, interesting that fast acid-OER catalysts, such as $\mathrm{RuO}_{2}$ and $\mathrm{IrO}_{2}$, are also fast WD catalysts.

Although the stability of the WD catalysts in the BPM have not been studied extensively, the observed trends (Figs. 2 and 3) cannot be explained by differences in WD catalyst stability nor dissolution (which might provide current-carrying ions or be coupled to WD). The electrolyzer measurements used pure water without soluble electrolyte, and therefore crossover of acid/base into the BPM junction is avoided. The best WD catalysts $\left(\mathrm{IrO}_{2}\right.$ in acid and $\mathrm{NiO}$ in base) should not substantially dissolve based on thermodynamic data (51). The rate of voltage increase for the BPM electrolyzer is also not correlated with $\eta_{\mathrm{wd}}$ (figs. S24 to S30) and continuous operation for $>4$ hours at $500 \mathrm{~mA} \cdot \mathrm{cm}^{-2}$ leads to an increase of only $40 \mathrm{mV}$ in the BPM electrolysis voltage (Fig. 4).

Taken together, these results help unify concepts of WD catalysis across the membrane and electrocatalysis sciences. The BPM electrolyzer architecture allows WD reaction rates to be directly probed, in relevant acidic or basic local-pH environments and independent of electron-transfer processes. Bifunctional HER catalysts, as demonstrated by others (34, 35) and shown here for $\mathrm{Pt} / \mathrm{TiO}_{2}$, can now be assembled based on independently measured WD activity. This approach should facilitate the design of electrocatalysts for any electrochemical process that uses water as a reactant (including the electrochemical reduction of $\mathrm{CO}_{2}$ and $\mathrm{N}_{2}$ ).

The BPMs fabricated here also have faster WD kinetics than those previously reported (see table $S 1$ for $\eta_{w d}$ values). The best BPMs, e.g., with $\mathrm{NiO}$ or $\mathrm{IrO}_{2}$ coated with 10 layers of $\mathrm{TiO}_{2}$ by ALD ( $\left.\mathrm{Ir} / \mathrm{TiO}_{2}-10 \mathrm{c}\right)$ at the AEL surface, and $\mathrm{RuO}_{2}$ or $\mathrm{IrO}_{2}$ at the CEL surface, show $\eta_{\mathrm{wd}}$ that is within measurement error $( \pm 9 \mathrm{mV})$ of $0 \mathrm{mV}$ at $20 \mathrm{~mA} \cdot \mathrm{cm}^{-2}$ in pure water at $50^{\circ} \mathrm{C}$. Fig. S31 shows a comparison of a $\mathrm{NiO} \mid \mathrm{IrO}_{2}$ bilayer BPM with other BPMs measured under comparable $\mathrm{H}$-cell conditions at $25^{\circ} \mathrm{C}$. Commercial membranes, e.g., from Fumatech, show $\eta_{\mathrm{wd}}$ ranging from 100 to $200 \mathrm{mV}$ (depending on pretreatment). Research BPMs generally show similar or substantially higher $\eta_{\mathrm{wd}}$ [see fig. S31, table S1, and (52)]. Figure 4 compares the polarization curves of our best BPM pure-water electrolyzers to reference alkaline-exchange-membrane (AEM) and proton-exchange-membrane (PEM) electrolyzers, made from the same membranes and OER/HER electrocatalysts. The BPM electrolyzers meet or exceed the performance of the AEM electrolyzers up to $400 \mathrm{~mA} \cdot \mathrm{cm}^{-2}$. This is possible because, in the AEM electrolyzer, Pt must drive HER in alkaline media with relatively slow kinetics. In the BPM electrolyzer, Pt drives HER with fast kinetics in a locally acidic environment, while protons are provided via catalyzed WD in the 
AEL/CEL junction. This result proves that $\eta_{\mathrm{wd}}$ is relatively small, even at high current densities, for the new BPMs reported here. State-of-the-art 3D-junction BPMs, similarly measured with acid and base on each side of the BPM, show $\eta_{\mathrm{wd}}$ of $\sim 1 \mathrm{~V}$ at $0.2 \mathrm{~A} \mathrm{~cm}^{-2}(24)$. Here we drive water electrolysis at $0.2 \mathrm{~A} \mathrm{~cm}^{-2}$ with a total voltage of $\sim 1.9 \mathrm{~V}$ and an estimated $\eta_{\mathrm{wd}}$ of $<0.25 \mathrm{~V}$. For current densities beyond $400 \mathrm{~mA} \cdot \mathrm{cm}^{-2}$, the BPM electrolyzer voltage is higher than that of the AEM electrolyzer. We ascribe this difference to water-transport limitations and ionic series resistance inside the BPM junction (see the supplementary materials).

Further innovations are possible to improve performance and achieve small $\eta_{\mathrm{wd}}$ at the $\sim 2 \mathrm{~A} \mathrm{~cm}^{-2}$ relevant to many technologies. Examples include engineering the surface-area and surface-chemistry of the WD catalyst, the number of different WD-catalyst layers, the interfacial area with a 3D junction (11, 24), the ionomer thickness and chemistry to improve water transport to the AEL/CEL junction, and the ionic conductivity in the WD catalyst layer. The performance decay (Fig. 4, inset), which may be related to junction dehydration at high currents, must also be mitigated prior to commercial application (see the supplementary materials).

The BPM enables electrochemical devices where ideal $\mathrm{pH}$ conditions can be selected independently for each half-reaction, in contrast to traditional architectures where electrode stability, catalyst activity and cost must be simultaneously optimized at both cathode and anode for a single $\mathrm{pH}$. This system-design flexibility could enable high-performance, nonprecious-metal, BPM electrolyzers. Earth-abundant metal oxides can be used to catalyze the WD reaction inside the BPM junction, with optimal earth-abundant OER catalysts (e.g., $\mathrm{Ni}_{x} \mathrm{Fe}_{y} \mathrm{O}_{z}$ ) at the basic anode and HER catalysts at the acidic cathode. Flow batteries that use anolyte and catholyte at different $\mathrm{pH}(53,54)$, (regenerative) fuel cells $(10)$, and direct $\mathrm{CO}_{2}$ electrolyzers that prevent soluble co-ion crossover (7), are other emerging applications facilitated by high-performance BPMs.

\section{REFERENCES AND NOTES}

1. T. Luo, S. Abdu, M. Wessling, Selectivity of ion exchange membranes: A review. J. Membr. Sci. 555, 429-454 (2018). doi:10.1016/i.memsci.2018.03.051

2. R. S. Reiter, W. White, S. Ardo, Electrochemical characterization of commercial bipolar membranes under electrolyte conditions relevant to solar fuels technologies. J. Electrochem. Soc. 163, H3132-H3134 (2016). doi:10.1149/2.0201604jes

3. Y. Tanaka, Ion Exchange Membranes: Fundamentals and Applications (Elesevier, 2007).

4. D. A. Vermaas, M. Sassenburg, W. A. Smith, Photo-assisted water splitting with bipolar membrane induced $\mathrm{pH}$ gradients for practical solar fuel devices. J. Mater. Chem. A Mater. Energy Sustain. 3, 19556-19562 (2015). doi:10.1039/C5TA06315A

5. Y. C. Li, D. Zhou, Z. Yan, R. H. Gonçalves, D. A. Salvatore, C. P. Berlinguette, T. E. Mallouk, Electrolysis of $\mathrm{CO}_{2}$ to syngas in bipolar membrane-based electrochemical cells. ACS Energy Lett. 1, 1149-1153 (2016). doi:10.1021/acsenergylett.6b00475

6. D. A. Vermaas, W. A. Smith, Synergistic electrochemical $\mathrm{CO}_{2}$ reduction and water oxidation with a bipolar membrane. ACS Energy Lett. 1, 1143-1148 (2016). doi:10.1021/acsenergylett.6b00557

7. Y. C. Li, Z. Yan, J. Hitt, R. Wycisk, P. N. Pintauro, T. E. Mallouk, Bipolar membranes inhibit product crossover in $\mathrm{CO}_{2}$ electrolysis cells. Adv. Sustainable Syst. 2 , 1700187 (2018). doi:10.1002/adsu.201700187

8. M. Lin, L. Han, M. R. Singh, C. Xiang, An experimental- and simulation-based evaluation of the $\mathrm{CO}_{2}$ utilization efficiency of aqueous-based electrochemical $\mathrm{CO}_{2}$ reduction reactors with ion-selective membranes. ACS Appl. Energy Mater. 2, 5843-5850 (2019). do:10.1021/acsaem.9b00986

9. Y. C. Li, G. Lee, T. Yuan, Y. Wang, D.-H. Nam, Z. Wang, F. P. García de Arquer, Y. Lum, C.-T. Dinh, O. Voznyy, E. H. Sargent, $\mathrm{CO}_{2}$ electroreduction from carbonate electrolyte. ACS Energy Lett. 4, 1427-1431 (2019). doi:10.1021/acsenergylett.9b00975

10. J. M. Ahlfield, L. Liu, P. A. Kohl, PEM/AEM junction design for bipolar membrane fuel cells. J. Electrochem. Soc. 164, F1165-F1171 (2017). doi:10.1149/2.1041712jes

11. C. H. Shen, R. Wycisk, P. N. Pintauro, High performance electrospun bipolar membrane with a 3D junction. Energy Environ. Sci. 10, 1435-1442 (2017). doi:10.1039/C7EE00345E

12. J. Balster, S. Srinkantharajah, R. Sumbharaju, I. Pünt, R. G. H. Lammertink, D. F. Stamatialis, M. Wessling, Tailoring the interface layer of the bipolar membrane.J. Membr. Sci. 365, 389-398 (2010). doi:10.1016/j.memsci.2010.09.034

13. S. S. Mel'nikov, O. V. Shapovalova, N. V. Shel'deshov, V. I. Zabolotskii, Effect of dmetal hydroxides on water dissociation in bipolar membranes. Petrol. Chem. 51, 577-584 (2011). doi:10.1134/S0965544111070097

14. A. M. Rajesh, T. Chakrabarty, S. Prakash, V. K. Shahi, Effects of metal alkoxides on electro-assisted water dissociation across bipolar membranes. Electrochim. Acta 66, 325-331 (2012). doi:10.1016/i.electacta.2012.01.102

15. F. Hanada, K. Hiraya, N. Ohmura, S. Tanaka, Bipolar membrane and method for its production. European Patent EPO459820B1 (1991).

16. Y. Oda, T. Yawataya, Neutrality-disturbance phenomenon of membrane-solution systems. Desalination 5, 129-138 (1968). doi:10.1016/S0011-9164(00)80208-8

17. M.-S. Kang, Y.-J. Choi, H.-J. Lee, S.-H. Moon, Effects of inorganic substances on water splitting in ion-exchange membranes. I. Electrochemical characteristics of ion-exchange membranes coated with iron hydroxide/oxide and silica sol. J. Colloid Interface Sci. 273, 523-532 (2004). doi:10.1016/i.jcis.2004.01.050 Medline

18. R. Simons, Strong electric field effects on proton transfer between membranebound amines and water. Nature 280, 824-826 (1979). doi:10.1038/280824a0

19. R. Simons, G. Khanarian, Water dissociation in bipolar membranes: Experiments and theory. J. Membr. Biol. 38, 11-30 (1978). doi:10.1007/BF01875160

20. H. Strathmann, H. J. Rapp, B. Bauer, C. M. Bell, Theoretical and practical aspects of preparing bipolar membranes. Desalination 90, 303-323 (1993). doi:10.1016/0011-9164(93)80183-N

21. A. B. Yaroslavtsev, V. V. Nikonenko, V. I. Zabolotsky, Ion transfer in ion-exchange and membrane materials. Russ. Chem. Rev. 72, 393-421 (2003). doi:10.1070/RC2003v072n05ABEH000797

22. V. I. Zabolotskii, N. V. Shel'deshov, N. P. Gnusin, Dissociation of water molecules in systems with ion-exchange membranes. Russ. Chem. Rev. 57, 801-808 (1988) doi:10.1070/RC1988v057n08ABEH003389

23. A. J. B. Kemperman, Handbook on Bipolar Membrane Technology (Twente Univ. Press, 2000).

24. Z. Yan, L. Zhu, Y. C. Li, R. J. Wycisk, P. N. Pintauro, M. A. Hickner, T. E. Mallouk, The balance of electric field and interfacial catalysis in promoting water dissociation in bipolar membranes. Energy Environ. Sci. 11, 2235-2245 (2018). doi:10.1039/C8EE01192C

25. S. Abdu, K. Sricharoen, J. E. Wong, E. S. Muljadi, T. Melin, M. Wessling, Catalytic polyelectrolyte multilayers at the bipolar membrane interface. ACS Appl. Mater. Interfaces 5, 10445-10455 (2013). doi:10.1021/am403019y Medline

26. M. Mogadam, A. Lervik, E. Riccardi, V. Venkatraman, B. K. Alsberg, T. S. van Erp Local initiation conditions for water autoionization. Proc. Natl. Acad. Sci. U.S.A. 115, E4569-E4576 (2018). doi:10.1073/pnas.1714070115 Medline

27. M. Eigen, L. d. Maeyer, Untersuchungen über die kinetik der neutralization. Z. Elecktrochem. 59, 986 (1955).

28. G. Ertl, H. Gerischer, Ein vergleich der kinetik der neutralisationsreaktionen des leichten und schweren wassers. Z. Elecktrochem. 66, 560 (1962). 
29. C. V. Ovesen, P. Stoltze, J. K. Nørskov, C. T. Campbell, A kinetic model of the water gas shift reaction. J. Catal. 134, 445-468 (1992). doi:10.1016/00219517(92)90334-E

30. M. Sterrer, N. Nilius, S. Shaikhutdinov, M. Heyde, T. Schmidt, H.-J. Freund, Interaction of water with oxide thin film model systems. J. Mater. Res. 34, $360-$ 378 (2019). doi:10.1557//imr.2018.454

31. P. A. Thiel, T. E. Madey, The interaction of water with solid surfaces: Fundamental aspects. Surf. Sci. Rep. 7, 211-385 (1987). doi:10.1016/0167-5729(87)90001-X

32. I. Bertini, C. Luchinat, "The reaction pathways of zinc enzymes and related biological catalysts," in Bioinorganic Chemistry (University Science Books, 1994), pp. 37-106.

33. D. Xu, M. B. Stevens, M. R. Cosby, S. Z. Oener, A. M. Smith, L. J. Enman, K. E. Ayers, C. B. Capuano, J. N. Renner, N. Danilovic, Y. Li, H. Wang, Q. Zhang, S. W. Boettcher, Earth-abundant oxygen electrocatalysts for alkaline anion-exchange-membrane water electrolysis: Effects of catalyst conductivity and comparison with performance in three-electrode cells. ACS Catal. 9, 7-15 (2019). doi:10.1021/acscatal.8b04001

34. N. Danilovic, R. Subbaraman, D. Strmcnik, K.-C. Chang, A. P. Paulikas, V. R. Stamenkovic, N. M. Markovic, Enhancing the alkaline hydrogen evolution reaction activity through the bifunctionality of $\mathrm{Ni}(\mathrm{OH})_{2} /$ metal catalysts. Angew. Chem. Int. Ed. 51, 12495-12498 (2012). doi:10.1002/anie.201204842 Medline

35. R. Subbaraman, D. Tripkovic, D. Strmcnik, K. C. Chang, M. Uchimura, A. P. Paulikas, V. Stamenkovic, N. M. Markovic, Enhancing hydrogen evolution activity in water splitting by tailoring $\mathrm{Li}^{+}-\mathrm{Ni}(\mathrm{OH})_{2}-\mathrm{Pt}$ interfaces. Science 334, 1256-1260 (2011). doi:10.1126/science. 1211934 Medline

36. X. Chen, I. T. McCrum, K. A. Schwarz, M. J. Janik, M. T. M. Koper, Co-adsorption of cations as the cause of the apparent $\mathrm{pH}$ dependence of hydrogen adsorption on a stepped platinum single-crystal electrode. Angew. Chem. Int. Ed. 56, 1502515029 (2017). doi:10.1002/anie.201709455 Medline

37. I. Ledezma-Yanez, W. D. Z. Wallace, P. Sebastián-Pascual, V. Climent, J. M. Feliu, M. T. M. Koper, Interfacial water reorganization as a pH-dependent descriptor of the hydrogen evolution rate on platinum electrodes. Nat. Energy 2, 17031 (2017). do: $10.1038 /$ nenergy.2017.31

38. J. Zheng, W. Sheng, Z. Zhuang, B. Xu, Y. Yan, Universal dependence of hydrogen oxidation and evolution reaction activity of platinum-group metals on $\mathrm{pH}$ and hydrogen binding energy. Sci. Adv. 2, e1501602 (2016). doi:10.1126/sciadv.1501602 Medline

39. M. Luo, Z. Wang, Y. C. Li, J. Li, F. Li, Y. Lum, D.-H. Nam, B. Chen, J. Wicks, A. Xu, T. Zhuang, W. R. Leow, X. Wang, C.-T. Dinh, Y. Wang, Y. Wang, D. Sinton, E. H. Sargent, Hydroxide promotes carbon dioxide electroreduction to ethanol on copper via tuning of adsorbed hydrogen. Nat. Commun. 10, 5814 (2019). doi:10.1038/s41467-019-13833-8 Medline

40. S. Z. Oener, S. Ardo, S. W. Boettcher, Ionic processes in water electrolysis: The role of ion-selective membranes. ACS Energy Lett. 2, 2625-2634 (2017). doi:10.1021/acsenergylett.7b00764

41. J. N. Mills, I. T. McCrum, M. J. Janik, Alkali cation specific adsorption onto fcc(111) transition metal electrodes. Phys. Chem. Chem. Phys. 16, 13699-13707 (2014). doi:10.1039/C4CP00760C Medline

42. E. Liu, J. Li, L. Jiao, H. T. T. Doan, Z. Liu, Z. Zhao, Y. Huang, K. M. Abraham, S. Mukerjee, Q. Jia, Unifying the hydrogen evolution and oxidation reactions kinetics in base by identifying the catalytic roles of hydroxyl-water-cation adducts. J. Am. Chem. Soc. 141, 3232-3239 (2019). doi:10.1021/jacs.8b13228 Medline

43. H. P. Boehm, Acidic and basic properties of hydroxylated metal oxide surfaces. Discuss. Faraday Soc. 52, 264-275 (1971). doi:10.1039/df9715200264

44. D. S. Smith, F. G. Ferris, Proton binding by hydrous ferric oxide and aluminum oxide surfaces interpreted using fully optimized continuous pKa spectra. Environ. Sci. Technol. 35, 4637-4642 (2001). doi:10.1021/es0018668 Medline

45. X. Liu, J. Cheng, X. Lu, R. Wang, Surface acidity of quartz: Understanding the crystallographic control. Phys. Chem. Chem. Phys. 16, 26909-26916 (2014). doi:10.1039/C4CP02955K Medline

46. M. K. Ridley, V. A. Hackley, M. L. Machesky, Characterization and surfacereactivity of nanocrystalline anatase in aqueous solutions. Langmuir 22, 1097210982 (2006). doi:10.1021/la061774h Medline

47. L. Onsager, Deviations from Ohm's law in weak electrolytes. J. Chem. Phys. 2 , 599-615 (1934). doi:10.1063/1.1749541
48. M. A. Blommaert, D. A. Vermaas, B. Izelaar, B. in 't Veen, W. A. Smith, Electrochemical impedance spectroscopy as a performance indicator of water dissociation in bipolar membranes. J. Mater. Chem. A Mater. Energy Sustain. 7, 19060-19069 (2019). doi:10.1039/C9TA04592A

49. H. Strathmann, J. J. Krol, H. J. Rapp, G. Eigenberger, Limiting current density and water dissociation in bipolar membranes. J. Membr. Sci. 125, 123-142 (1997). doi:10.1016/S0376-7388(96)00185-8

50. I. C. Man, H.-Y. Su, F. Calle-Vallejo, H. A. Hansen, J. I. Martínez, N. G. Inoglu, J. Kitchin, T. F. Jaramillo, J. K. Nørskov, J. Rossmeisl, Universality in oxygen evolution electrocatalysis on oxide surfaces. ChemCatChem 3, 1159-1165 (2011). doi:10.1002/cctc.201000397

51. M. Pourbaix, Atlas of Electrochemical Equilibria in Aqueous Solutions (National Association of Corrosion, 1974)

52. M. B. McDonald, S. Ardo, N. S. Lewis, M. S. Freund, Use of bipolar membranes for maintaining steady-state $\mathrm{pH}$ gradients in membrane-supported, solar-driven water splitting. ChemSusChem 7, 3021-3027 (2014) doi:10.1002/cssc. 201402288 Medline

53. M. Park, E. S. Beh, E. M. Fell, Y. Jing, E. F. Kerr, D. Porcellinis, M.-A. Goulet, J. Ryu, A. A. Wong, R. G. Gordon, J. Cho, M. J. Aziz, A high voltage aqueous zinc-organic hybrid flow battery. Adv. Energy Mater. 9, 1900694 (2019). doi:10.1002/aenm.201900694

54. J. Xia, G. Eigenberger, H. Strathmann, U. Nieken, Flow battery based on reverse electrodialysis with bipolar membranes: Single cell experiments. J. Membr. Sci. 565, 157-168 (2018). doi:10.1016/j.memsci.2018.07.073

55. S. Z. Oener, M. J. Foster, S. W. Boettcher, Tabulated data for: Accelerating water dissociation in bipolar membranes and for electrocatalysis. Zenodo (2020); https://doi.org/10.5281/zenodo.3897673.

56. W. Zhao, M. Bajdich, S. Carey, A. Vojvodic, J. K. Nørskov, C. T. Campbell, Water dissociative adsorption on $\mathrm{NiO}(111)$ : Energetics and structure of the hydroxylated surface. ACS Catal. 6, 7377-7384 (2016). doi:10.1021/acscatal.6b01997

57. H. Ali, R. Seidel, A. Bergmann, B. Winter, Electronic structure of aqueous-phase anatase titanium dioxide nanoparticles probed by liquid jet photoelectron spectroscopy. J. Mater. Chem. A Mater. Energy Sustain. 7, 6665-6675 (2019). doi:10.1039/C8TA09414D

58. K. N. Grew, J. P. McClure, D. Chu, P. A. Kohl, J. M. Ahlfield, Understanding transport at the acid- alkaline interface of bipolar membranes. J. Electrochem. Soc. 163 F1572-F1587 (2016). doi:10.1149/2.0941614jes

59. F. G. Wilhelm, I. Pünt, N. F. A. van der Vegt, H. Strathmann, M. Wessling, Asymmetric bipolar membranes in acid-base electrodialysis. Ind. Eng. Chem. Res. 41, 579-586 (2002). doi:10.1021/ie010524n

60. M. A. Henderson, The interaction of water with solid surfaces: Fundamental aspects revisited. Surf. Sci. Rep. 46, 1-308 (2002). doi:10.1016/S0167$5729(01) 00020-6$

61. I. T. McCrum, M. J. Janik, pH and alkali cation effects on the Pt cyclic voltammogram explained using density functional theory. J. Phys. Chem. C 120, 457-471 (2016). doi:10.1021/acs.jpcc. 5 b10979

62. T. Reier, M. Oezaslan, P. Strasser, Electrocatalytic oxygen evolution reaction (OER) on Ru, Ir, and Pt catalysts: A comparative study of nanoparticles and bulk materials. ACS Catal. 2, 1765-1772 (2012). doi:10.1021/cs3003098

63. J. J. Krol, M. Jansink, M. Wessling, H. Strathmann, Behaviour of bipolar membranes at high current density: Water diffusion limitation. Separ. Purif. Tech. 14, 41-52 (1998). doi:10.1016/S1383-5866(98)00058-6

64. N. V. Shel'deshov, V. I. Zabolotskii, V. V. Ganych, The effect of insoluble metal hydroxides on the reaction rate of water dissociation on a cation-exchange membrane. Elektrokhimiya 30, 1458-1461 (1994).

65. J. Balster, R. Sumbharaju, S. Srikantharajah, I. Punt, D. F. Stamatialis, V. Jordan, M. Wessling, Asymmetric bipolar membrane: A tool to improve product purity. J. Membr. Sci. 287, 246-256 (2007). doi:10.1016/i.memsci.2006.10.042

66. Q. Y. Wang, B. Wu, C. X. Jiang, Y. M. Wang, T. W. Xu, Improving the water dissociation efficiency in a bipolar membrane with amino-functionalized MIL-101. J. Membr. Sci. 524, 370-376 (2017). doi:10.1016/i.memsci.2016.11.056

67. A. M. Rajesh, M. Kumar, V. K. Shahi, Functionalized biopolymer based bipolar membrane with poly ethylene glycol interfacial layer for improved water splitting. J. Membr. Sci. 372, 249-257 (2011). doi:10.1016/i.memsci.2011.02.009

68. R. Q. Fu, T. W. Xu, W. H. Yang, Z. X. Pan, Fundamental studies on the intermediate 
layer of a bipolar membrane. Part II. Effect of bovine serum albumin (BSA) on water dissociation at the interface of a bipolar membrane. J. Colloid Interface Sci. 278, 318-324 (2004). Medline

69. R. Q. Fu, Y. Y. Cheng, T. W. Xu, W. H. Yang, Fundamental studies on the intermediate layer of a bipolar membrane. Part VI. Effect of the coordinated complex between starburst dendrimer PAMAM and chromium (III) on water dissociation at the interface of a bipolar membrane. Desalination 196, 260-265 (2006). doi:10.1016/i.desal.2006.03.009

70. R.-Q. Fu, Y.-H. Xue, T.-W. Xu, W.-H. Yang, Fundamental studies on the intermediate layer of a bipolar membrane part IV. Effect of polyvinyl alcohol (PVA) on water dissociation at the interface of a bipolar membrane. J. Colloid Interface Sci. 285, 281-287 (2005). doi:10.1016/i.jcis.2004.11.050 Medline

71. Y. Xue, T. Xu, R. Fu, Y. Cheng, W. Yang, Catalytic water dissociation using hyperbranched aliphatic polyester (Boltorn series) as the interface of a bipolar membrane. J. Colloid Interface Sci. 316, 604-611(2007). doi:10.1016/i.jicis.2007.08.052 Medline

72. M. B. McDonald, M. S. Freund, Graphene oxide as a water dissociation catalyst in the bipolar membrane interfacial layer. ACS Appl. Mater. Interfaces 6, 1379013797 (2014). doi:10.1021/am503242v Medline

73. M. Kosmulski, Surface Charging and Points of Zero Charge (CRC, 2009).

\section{ACKNOWLEDGMENTS}

Mark Lonergan is thanked for assistance in developing the numerical simulations, Shane Ardo for insightful discussions regarding BPM physics and ion-transfer reactions, and Jessica Fehrs for assistance analyzing ion-crossover rates.

Funding: This work was supported by the National Science Foundation Chemical Catalysis program under Grant CHE-1566348. S.Z.0 acknowledges support from a research fellowship of the German Research Foundation (Deutsche

Forschungsgemeinschaft) under project number 408246589 (OE 710/1-1). We acknowledge use of shared instrumentation in the CAMCOR and Rapid Materials Prototyping facilities, which are supported by grants from the M. J. Murdock Charitable Trust, the W. M. Keck Foundation, ONAMI, and the NSF. Author contributions: S.Z.O and S.W.B. conceived of the project, analyzed the data, and wrote the manuscript. S.Z.O. completed the experiments with assistance from M.J.F. Competing interests: S.Z.O, S.W.B., and M.J.F have filed a provisional patent application (No.62/984,652) based on the results of this manuscript. Data and materials availability: Tabulated data are available in the Zenodo repository (55).

\section{SUPPLEMENTARY MATERIALS}

science.sciencemag.org/cgi/content/full/science.aaz1487/DC1

Materials and Methods

Supplementary Text

Figs. S1 to S36

Tables S1 and S2

References (56-73)

15 August 2019; resubmitted 20 December 2019

Accepted 22 June 2020

Published online 2 July 2020

10.1126/science.aaz1487 


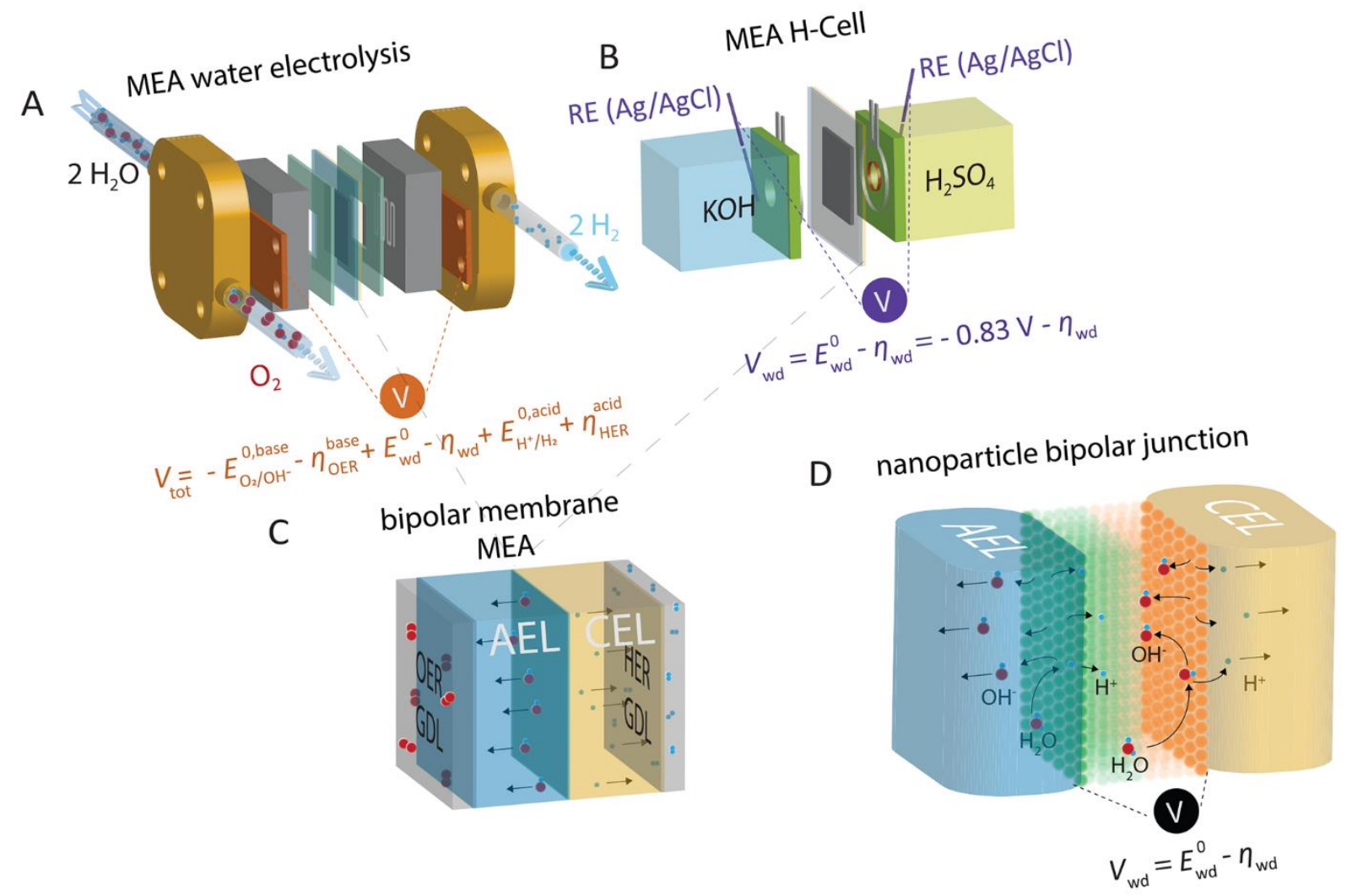

Fig. 1. Bipolar-membrane water-dissociation measurements. (A) WD is studied in an electrolyzer fed only pure water. The applied $V_{\text {tot }}$ is negative, associated with the positive $\Delta G_{r \times n}$ of water electrolysis. We define $\eta_{w d}$ as positive. (B) A custom $\mathrm{H}$-cell allows for the direct measurement of $\eta_{w d}$ to calibrate the electrolysis setup. (C) The membrane-electrode assembly (MEA) is kept under constant mechanical pressure preventing delamination. The MEA is composed of the anode and cathode gas-diffusion layers (GDLs) with $\mathrm{IrO}_{2} \mathrm{OER}$ catalyst and Pt HER catalyst, the AEL and CEL, and the WD catalyst. (D) Different nanoparticle WD catalysts can be placed on both the acidic CEL and basic AEL surfaces. 
A

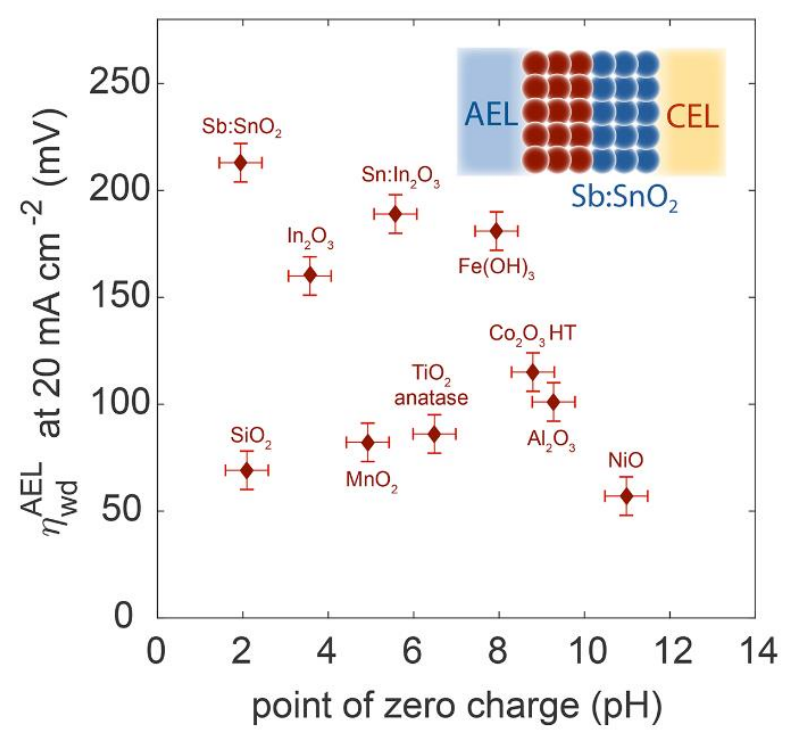

B

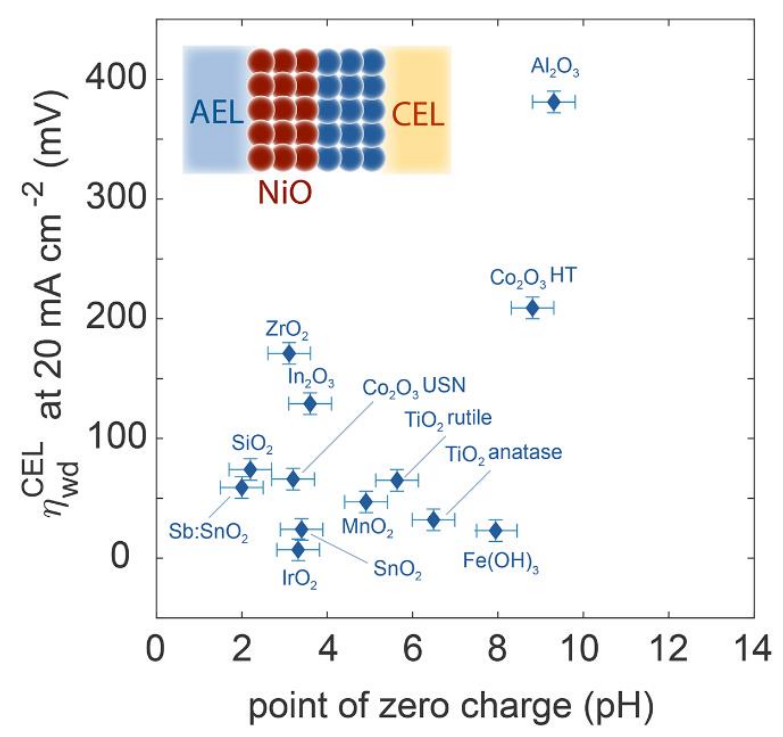

Fig. 2. WD overpotentials and the point of zero charge (PZC) for oxide nanoparticles. (A) Values for $\eta_{w d}$ measured with catalysts placed under locally alkaline conditions in the BPM ( $\left.\eta_{w d}^{\mathrm{AEL}}\right)$, by using acidstable $\mathrm{Sb}: \mathrm{SnO}_{2}$ to cover the acidic CEL. (B) Values for $\eta_{\text {wd }}$ measured with catalysts placed under locally acidic conditions ( $\eta_{\mathrm{wd}}^{\mathrm{CEL}}$ ), by using base-stable $\mathrm{NiO}$ to coat the alkaline AEL. The PZCs were measured by finding the $\mathrm{pH}$ where the zeta potential (at the hydrodynamic shear plane) tended to zero. The uncertainties in the PZC data are based on measurements made in triplicate (see the supplementary materials and fig. S16), while those for $\eta_{w d}$ reflect the uncertainty of the calibration of the MEA with the $\mathrm{H}$-cell setup (see the supplementary materials and figs. S4 to S6). 
A

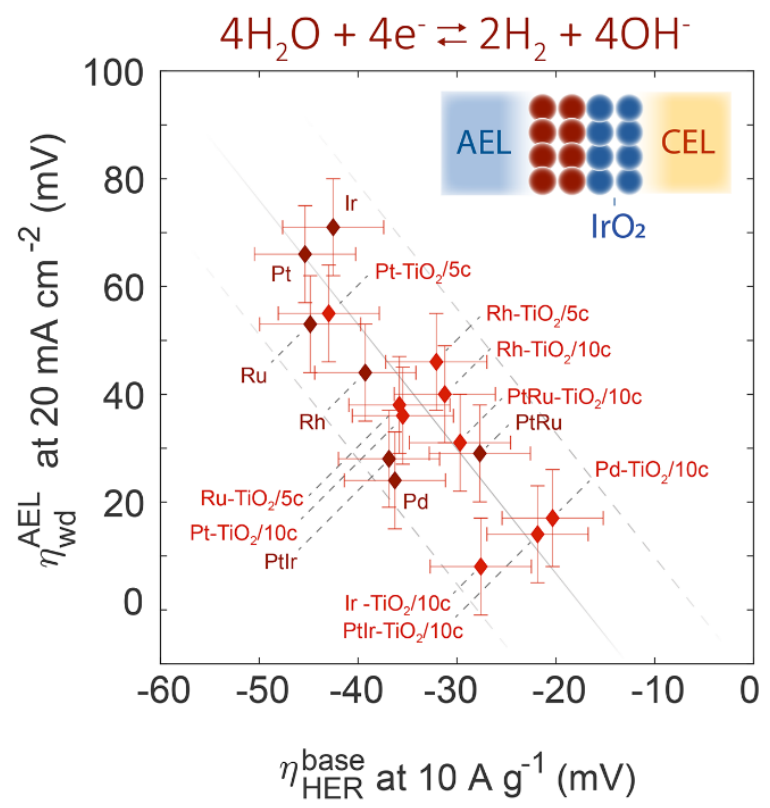

C

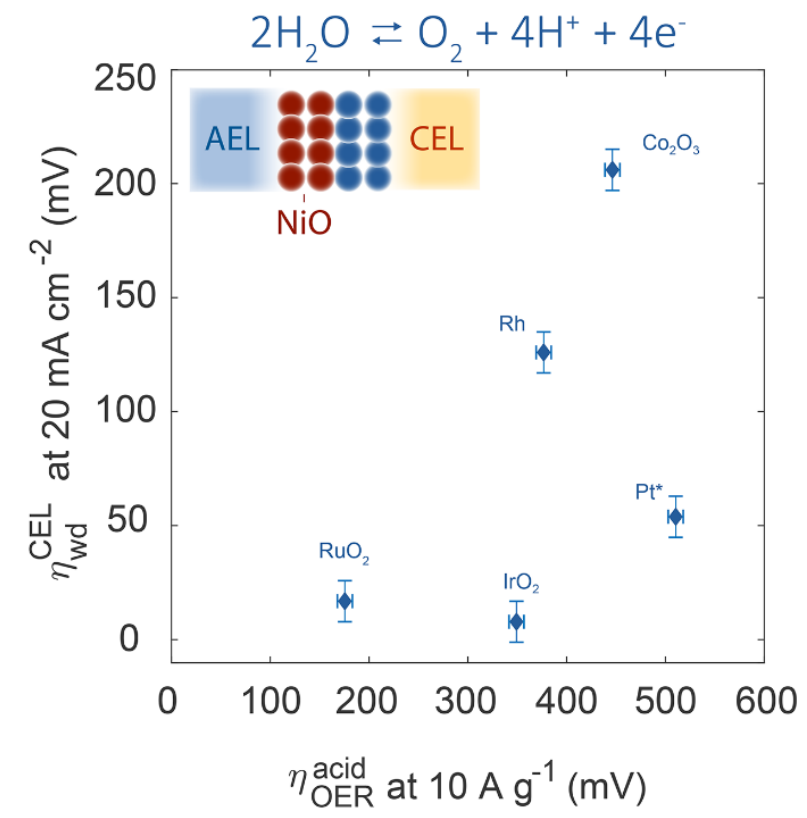

B acid HER catalysts

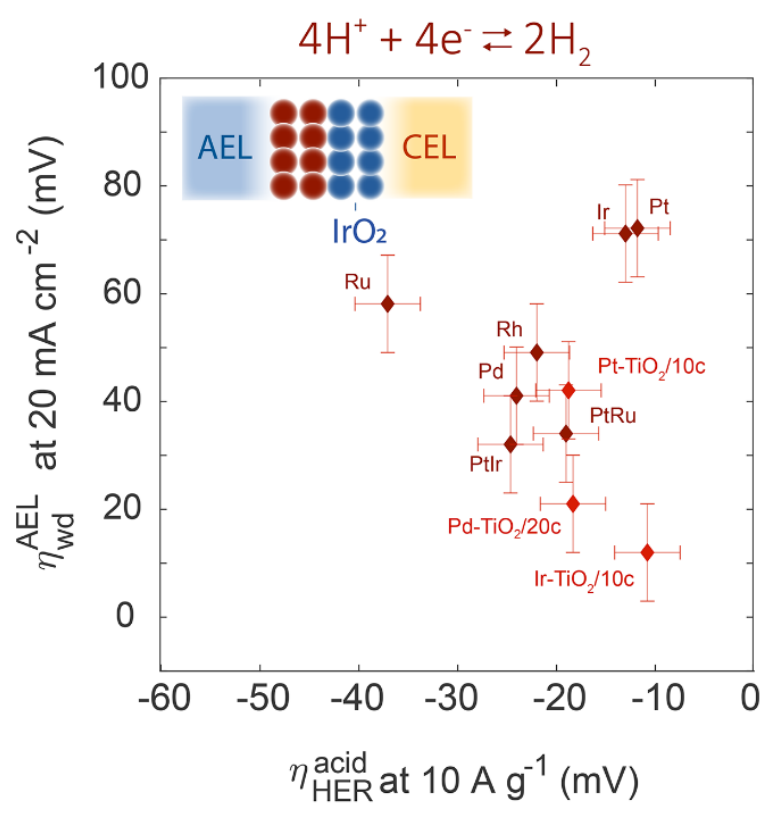

D base OER catalysts

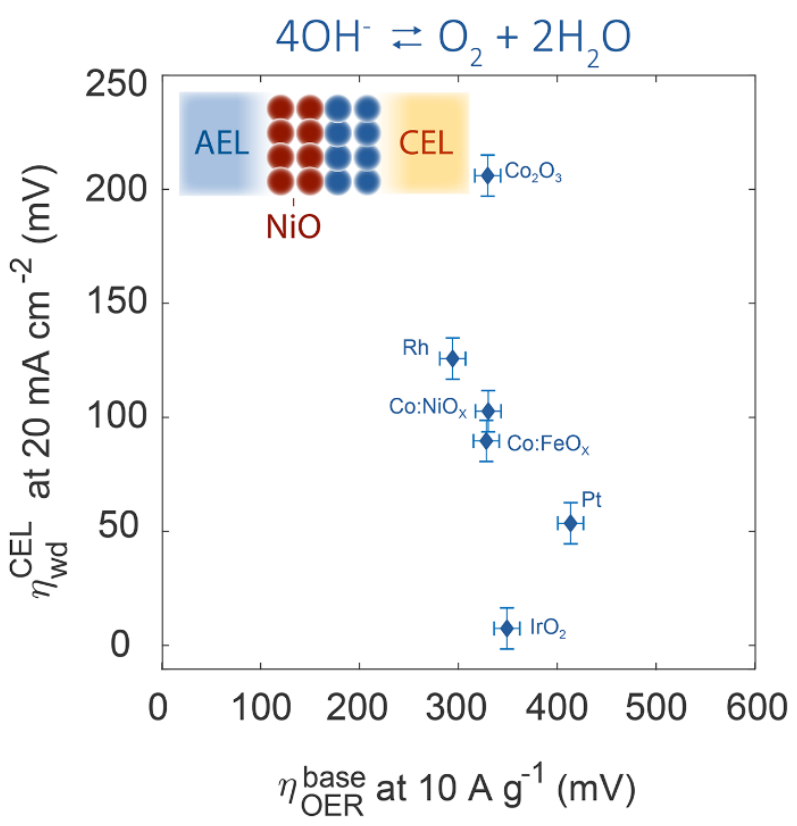


Fig. 3. Comparison between WD and electrocatalytic overpotentials measured on the same nanoparticles. (A) The overpotentials for WD in a locally basic environment (with $\mathrm{IrO}_{2}$ used as the stable WD catalyst on the acidic CEL surface) correlate with the overpotentials measured for HER in $1.0 \mathrm{M} \mathrm{KOH}\left[\rho\left(\eta_{\mathrm{HER}}^{\text {base }}, \eta_{\mathrm{wd}}^{\mathrm{AEL}}\right)=-0.81\right]$, consistent with WD rate-limiting the alkaline HER. (B) No correlation is found between $\eta_{w d}$ and the HER performance in $1.0 \mathrm{M} \mathrm{H}_{2} \mathrm{SO}_{4}$ $\left[\rho\left(\eta_{\mathrm{HER}}^{\text {acid }}, \eta_{\mathrm{wd}}^{\mathrm{AEL}}\right)=-0.13\right]$, consistent with WD not being involved in the acidic HER mechanism. Dark-green markers in (A) and (B) show the as-received nanoparticles and light-green markers samples after $\mathrm{TiO}_{2}$ decoration. (C) The $\eta_{w d}$ in a locally acidic environment (with $\mathrm{NiO}$ used as the stable WD catalyst on the basic AEL surface) do not strongly correlate with the overpotentials measured for OER in $1.0 \mathrm{M} \mathrm{H}_{2} \mathrm{SO}_{4}\left[\rho\left(\eta_{\mathrm{OER}}^{\text {acid }}, \eta_{\mathrm{wd}}^{\mathrm{CEL}}\right)=0.49\right]$, consistent with WD not being rate-limiting. (D) No strong correlation is present between $\eta_{w d}$ and the OER overpotentials in $1.0 \mathrm{M} \mathrm{KOH}$ $\left[\rho\left(\eta_{\mathrm{OER}}^{\mathrm{base}}, \eta_{\mathrm{wd}}^{\mathrm{CEL}}\right)=-0.45\right]$, consistent with the large $\mathrm{OH}^{-}$concentration obviating the need for WD. The loadings for the electrocatalysis studies were 0.1 to $1 \mathrm{mg} \cdot \mathrm{cm}^{-2}$, and the current densities were 1 to $10 \mathrm{~mA} \cdot \mathrm{cm}^{-2}$, similar to the WD current densities studied in the BPM. The currents for the electrocatalysts are normalized to mass, because higher loadings lead to larger current. The WD current was not normalized to mass, because a simple correlation between activity and loading does not exist (see fig. S8). The uncertainties for the OER and HER overpotentials are based on the average standard deviation obtained for each electrolyte condition, while those for $\eta_{w d}$ reflect the uncertainty of the MEA calibration with the H-cell setup (see the supplementary materials and figs. S4 to S6). We note that the Pt OER activity degraded with subsequent cycles due to oxidation (see the supplementary materials). 


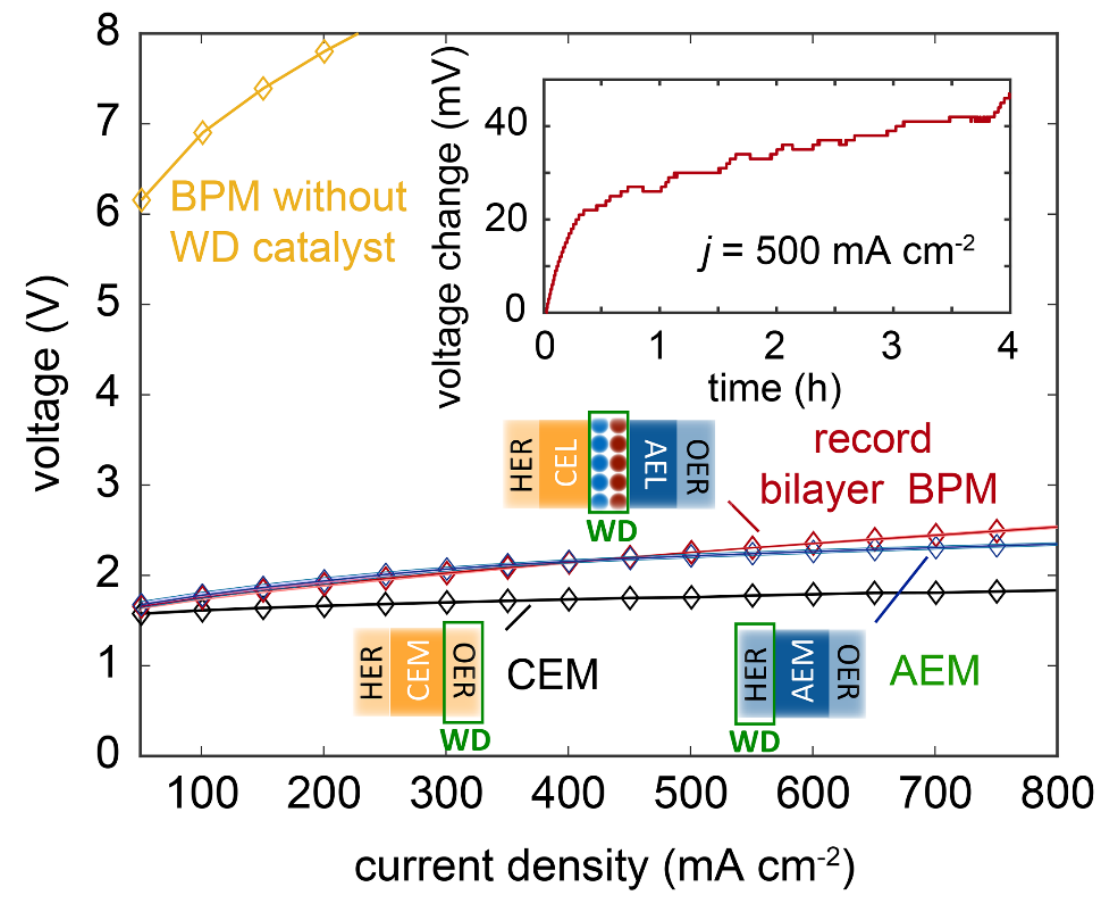

Fig. 4. Alkaline, acidic, and bipolar membrane electrolyzers. BPM electrolyzers require $>6 \mathrm{~V}$ to drive electrolysis at $50 \mathrm{~mA} \cdot \mathrm{cm}^{-2}$ without additional WD catalysts (yellow). When the new bilayer WD catalysts are added, the performance dramatically improves and is similar to a reference AEM electrolyzer. The PEM electrolyzer performs better, which is likely due to the superior properties of Nafion ${ }^{\oplus}$ compared to Sustainion'. For all electrolyzers, the cathode and anode catalyst composition and loading were identical. The AEM and bilayer BPM electrolyzer polarization curves are averages over three devices/datasets with the error indicated by the thickness of the line (fig. S32). The inset shows that the BPM electrolyzer performance is relatively stable over 4 hours of operation at $500 \mathrm{~mA} \cdot \mathrm{cm}^{-2}$ (see the supplementary materials for discussion of degradation modes and mitigation strategies). 